\title{
Mariolina Bertini, Dal palcoscenico al romanzo: l'“Olympia" di Balzac e il 'mélodrame'
}

\section{Marco Stupazzoni}

\section{(2) OpenEdition}

1 Journals

\section{Edizione digitale}

URL: http://journals.openedition.org/studifrancesi/3788

DOI: 10.4000/studifrancesi.3788

ISSN: 2421-5856

\section{Editore}

Rosenberg \& Sellier

\section{Edizione cartacea}

Data di pubblicazione: 1 décembre 2012

Paginazione: 588-589

ISSN: 0039-2944

\section{Notizia bibliografica digitale}

Marco Stupazzoni, «Mariolina Bertini, Dal palcoscenico al romanzo: I"Olympia" di Balzac e il 'mélodrame'»,

Studi Francesi [Online], 168 (LVI | III) | 2012, online dal 30 novembre 2015, consultato il 06 mars 2021.

URL: http://journals.openedition.org/studifrancesi/3788; DOI: https://doi.org/10.4000/studifrancesi. 3788

Questo documento è stato generato automaticamente il 6 mars 2021.

\section{(c) $(1) \ominus$}

Studi Francesi è distribuita con Licenza Creative Commons Attribuzione - Non commerciale - Non opere derivate 4.0 Internazionale. 
Mariolina Bertini, Dal palcoscenico al romanzo: l'"Olympia" di Balzac e il 'mélodrame'

Marco Stupazzoni 


\section{NOTIZIA}

MARIOLINA BERTINI, Dal palcoscenico al romanzo: l'“Olympia” di Balzac e il 'mélodrame', in Aa. Vv., Contatti Passaggi Metamorfosi. Studi di letteratura francese e comparata in onore di Daniela Dalla Valle, a cura di Gabriella Bosco, Monica PAVESIO, Laura RESCIA, Roma, Edizioni di storia e letteratura, «Temi e testi», 2010, pp. 245-258.

1 Il rilievo ed il fascino che il genere melodrammatico assume nell'opera balzachiana trova un motivo di grande interesse nell'affiorare del ricordo di un mélodrame del 1808 Olimpia ou la caverne de Strozzi, dovuto a un certo F-B. Gilbert - nell'enigmatico ed esilarante récit-pastiche di Balzac Fragments d'un roman publié sous l'Empire par un auteur inconnu [Olympia ou les vengeances romaines]. Il riferimento intertestuale è presente sia nella prima versione del 1833, sia nelle successive edizioni del 1834 e del 1843, al momento dell'inserimento nella Muse du département. È proprio sulle suggestive allusioni di questa reminiscenza melodrammatica che riflette con acume M. Bertini in questo studio. Balzac imbastisce il pastiche di un romanzo impregnato di suggestioni melodrammatiche e «trasforma alcuni spunti della pièce del 1808 negli elementi portanti di un tipico roman noir» (p. 247). Dissimulando nelle versioni del 1833 e del 1834 (pubblicata nel «Voleur») la sua nostalgia per il mélodrame, Balzac aderisce all'abituale condanna di questo genere letterario «come genere ingenuo, stereotipato e di scarso valore letterario» (p. 257). Ma la diversa scelta operata nel 1843 «ricolloca il mélodrame e si suoi autori tra le realtà che si possono nominare senza vergogna» (p. 258). In questo senso, la citazione esplicita di Pixerecourt e del mélodrame nella Muse du département assume il valore di un omaggio nostalgico ed affettuoso. 